\title{
Morphological and Molecular Dissection of Leaf Development in Wild-Type and Various Morphogenetic Mutants in Rice
}

\author{
Punyavee Dechkrong1, Takanori Yoshikawa ${ }^{2}$, Jun-Ichi Itoh ${ }^{*}$ \\ ${ }^{1}$ Graduate School of Agricultural and Life Sciences, University of Tokyo, Tokyo, Japan \\ ${ }^{2}$ School of Agricultural Regional Vitalization, Kibi International University, Minamiawaji, Japan \\ Email: ${ }^{*}$ ajunito@mail.ecc.u-tokyo.ac.jp
}

Received 30 April 2015; accepted 23 May 2015; published 26 May 2015

Copyright (C) 2015 by authors and Scientific Research Publishing Inc.

This work is licensed under the Creative Commons Attribution International License (CC BY). http://creativecommons.org/licenses/by/4.0/

(c) (i) Open Access

\begin{abstract}
Leaf cells undergo two main developmental events; i.e., cell proliferation and cell differentiation, before maturation. These events occur sequentially at specific positions and with specific timing during leaf development. To understand the transition from cell proliferation to cell differentiation of rice leaves, we analyzed rice leaves from both morphological and molecular viewpoints. The results of anatomical, morphological, and histochemical analyses indicated that P4 leaf primordium is the stage when dynamic transition of the cellular state from immature to mature along the proximal-distal axis of the leaf occurs. We screened for marker genes showing a dynamic expression pattern along the proximal-distal axis of the P4 leaf, and applied them to expression analysis in wild-type and various morphogenetic mutants. The changes in expression pattern of the marker genes varied between developmental stages and between mutants. Our analysis reinforced previous data regarding the developmental transition of wild-type rice leaves and indicated that the transition can be monitored using our molecular markers. The results of this study indicate that expression analysis using these molecular markers would be valuable for understanding the genetic effects on leaf development in various leaf morphogenetic mutants.
\end{abstract}

\section{Keywords}

Rice, Leaf Development, Cell Proliferation, Cell Differentiation, TCP (TEOSINTE BRANCHED1/CYCLOIDEA/PCF), GRF (GROWTH-REGULATING FACTOR)

\footnotetext{
"Corresponding author.
}

How to cite this paper: Dechkrong, P., Yoshikawa, T. and Itoh, J.-I. (2015) Morphological and Molecular Dissection of Leaf Development in Wild-Type and Various Morphogenetic Mutants in Rice. American Journal of Plant Sciences, 6, $1215-1232$. http://dx.doi.org/10.4236/ajps.2015.68125 


\section{Introduction}

As the major sites of photosynthesis, leaves are crucial organs of higher plants. Young leaves originate from the flank of shoot apical meristem and undergo various developmental events; i.e., axis determination, cell proliferation, cell elongation, cell differentiation, and tissue differentiation. Various aspects of leaf development have been studied, and the mechanisms of spatiotemporal control of cell proliferation and cell differentiation at key events. The genetic mechanism underlying the transition from cell proliferation to cell differentiation during leaf development has been the subject of intensive study.

The duration and activity of cell proliferation during leaf development are regulated under a complex genetic cascade. The genetic factors operating most downstream of the cascade are cell cycle-related genes. Cyclins and their partners, cyclin-dependent kinases (CDKs), are targets of cell division control [1] [2]. In Arabidopsis, an altered expression level of the cyclin gene, $C Y C D 3$, was shown to affect the shape and cell number of leaves by modulating cell proliferation [3]. Overexpression of the CDK inhibitor gene, KRP2, resulted in production of small and serrated leaves, although the temporal patterns of cell division and differentiation were unaffected [4]. Several regulators of cell proliferation and cell differentiation processes have been identified. Members of the TCP (TEOSINTE BRANCHED1/CYCLOIDEA/PCF) gene family, encoding plant-specific transcription factors, act to regulate multiple developmental pathways, particularly cell proliferation in developing organs. Although the mechanism by which TCP genes regulate cell proliferation is largely unknown, some TCP genes were shown to directly regulate cell cycle regulators. TCP20 of Arabidopsis binds to the promoter of $C Y C B 1 ; 1$, which controls cell cycle G2/M progression and positively regulates cell proliferation [5]. TCP genes also function as negative regulators or coordinators of cell proliferation during leaf development. In addition to TCP, the cooperative action of GRF (GROWTH-REGULATING FACTOR) genes is important for regulating cell proliferation during leaf development. GRFs encode putative plant-specific transcription factors and function as positive regulators of cell proliferation, and they are largely expressed in tissues with high degrees of cell proliferation [6]. Lossof-function of multiple GRF genes showed reduced leaf size and cell number in Arabidopsis, suggesting that GRFs play redundant roles in modulation of cell proliferation [3] [6] [7]. GRF expression is controlled by the microRNA species, miR396, the accumulation level of which is lower in developing leaves and gradually increases during development, with an inverse distribution to that of GRF expression [6] [7]. Overexpression of miR396 affects cell proliferation by reducing cell number, thus resulting in narrow leaves [7]-[9]. Although TCP and GRF transcription factor genes are thought to be important regulators of leaf proliferation, it has been suggested that many genetic factors affect the pattern of leaf proliferation.

The effects of these genetic factors on leaf development have been validated mainly in the model dicotyledonous plant, Arabidopsis thaliana. However, as the patterns of determination of developmental events differ among plant species, it is necessary to study these processes in species other than Arabidopsis to gain insight into the universal mechanism underlying regulation of leaf developmental in higher plants. The basic pattern of leaf growth is different between monocot and dicot species. In Arabidopsis, although the leaf blade and leaf petiole differentiate along the proximal-distal axis during development, cell proliferation activity for leaf blade expansion is observed along both the proximal-distal and mediolateral axes. Recently, proliferative activity was found in the junction of the leaf blade and leaf petiole in early leaf development, suggesting that proliferative cells in this region establish both leaf blade and leaf petiole in a bidirectional manner [10]. In contrast, the pattern of leaf growth in grass species, such as maize and rice, is mostly linear, and the proliferating cells are mainly located in the leaf base after establishment of the outline of the leaf [11] [12].

Grass species are suitable for studying control of the transition from cell proliferation to cell differentiation during leaf development, because leaf differentiation proceeds sequentially from the tip to the base, and the process can be observed at specific stages of the leaf primordium along the proximal-distal axis. Several recent analyses focusing on the establishment of photosynthetic function during leaf development have been reported in maize and rice [12] [13]. The results indicated that the sink source boundary of photosynthetic product was established during the young leaf primordium stage, with the sink region located at the basal part and chloroplast differentiation at the apical part of the specific stage of the leaf primordium [12] [13]. Thus, dynamic transition processes, not only in development but also in physiological traits, occur along the leaf axis in young leaves of grasses. It was predicted that thousands of genes are involved in this transition process. In fact, $68 \%$ of the annotated genes showed dynamic expression patterns along the proximal-distal axis of younger leaves in maize [11]. However, the genetic mechanism regulating the transition from cell proliferation to cell differentiation 
during leaf development is still unclear. Rice is a good candidate for genetic studies of leaf development in grass species, because it is expected that genetic regulation of rice leaf development will rapidly progress using genome editing-based reverse genetics. For the first step in the elucidation of the molecular mechanisms governing leaf development in rice, we examined rice leaves during morphogenesis to obtain basic information regarding the developmental transition by morphological, anatomical, and histochemical analyses. Based on the information thus obtained, the optimal stage of leaf primordium for analysis and genetic markers reflecting the developmental transition were selected, and were applied to various morphogenetic mutants. Our results provide basic knowledge regarding the developmental transition, and we also present case studies regarding genetic effects on the transition process.

\section{Materials and Methods}

\subsection{Plant Materials}

Two wild-type rice varieties (cv. Nipponbare and Taichung65) and mutant lines, T65lg, pla1-4, dl-5, d18h, $T 65 d 1$, and $d 61-2$, were grown in a greenhouse around $30^{\circ} \mathrm{C} / 20^{\circ} \mathrm{C}$ (day/night). About 15 days after sowing (DAS), leaves of Nipponbare seedlings were sampled to examine the anatomy and morphology. Taichung65 and mutants were used for expression analysis.

\subsection{Scanning Electron Microscopy}

Rice seedlings were dissected and separated into P3 to P6 leaf primordia, and shoot apex containing P1 and P2. They were fixed with PFA solution (4\% paraformaldehyde in $0.1 \mathrm{M}$ Na-phosphate buffer, $1 \%$ Triton-X) overnight, and then rinsed with $0.1 \mathrm{M}$ Na-phosphate buffer for 1 hour, dehydrated through a graded EtOH series, and then $100 \% \mathrm{EtOH}$ was replaced with liquidized $t$-butyl alcohol by incubation at $37^{\circ} \mathrm{C}$ overnight. Samples were frozen at $-20^{\circ} \mathrm{C}$ for 10 minutes, and completely dried using a critical point dryer (model JFD-320; JEOL, Tokyo, Japan). The samples were coated with platinum (Ion sputter E-1030; Hitachi, Tokyo, Japan) and observed by scanning electron microscopy (model S-4000; Hitachi) at $10 \mathrm{keV}$.

\subsection{Anatomical Analysis}

For plastic sections, leaf blades, leaf sheaths, and leaf collars of P5 and P6 leaf primordia were fixed with PFA solution overnight, rinsed with $0.1 \mathrm{M}$ Na-phosphate buffer for 1 hour, and dehydrated through a graded EtOH series, followed by infiltration with Technovit 7100 (Heraeus Kulzer) for 4 days and embedded. Samples were cut into Section $3 \mu \mathrm{m}$ thick using a rotary microtome (model HM360; MicroEdge, Tokyo, Japan), stained with $0.5 \%$ Toluidine Blue $\mathrm{O}$ in $0.1 \%$ sodium carbonate buffer, and observed by light microscopy (model AX80; Olympus, Tokyo, Japan). For paraffin sections, the P4 leaf primordium was separated into four parts, which were fixed with PFA solution, and finally embedded in Paraplast Plus (Oxford Labware, St. Louis, MO). All samples were cut into Sections $8 \mu \mathrm{m}$ thick and stained with hematoxylin, $1 \%$ Safranin-O, and $1 \%$ Fast-Green, and then examined by light microscopy.

\subsection{Histochemical Analysis}

To observe starch and lignified cell walls, cross-sections of eight segments of P4 leaves were subjected to staining with iodine-potassium-iodide (IKI) solution and by double staining with Safranin-O and Orange-G, respectively. For observation of chloroplasts, autofluorescence of the cross-sections of eight segments were observed by fluorescence microscopy (model BX60; Olympus).

\subsection{RT-PCR and Real-Time PCR Analysis}

Wild-type and mutant samples were frozen in liquid nitrogen, and total RNA was extracted using TRIzol reagent (Invitrogen, Carlsbad, CA). First-strand cDNA was synthesized using High-Capacity cDNA Reverse Transcription Kits (Invitrogen). Semi-quantitative RT-PCR analysis was performed for appropriate cycles of $25^{\circ} \mathrm{C}$ for 10 minutes, $37^{\circ} \mathrm{C}$ for 120 minutes, and $85^{\circ} \mathrm{C}$ for 5 minutes. For real-time PCR, TaqMan assay was performed using TaqMan ${ }^{\circledR}$ Fast Universal PCR Master Mix (2×) (Applied Biosystems, Foster City, CA) and FAM-labeled TaqMan probes for each gene (StepOnePlus real-time PCR system; Applied Biosystems). The expression level of 
each sample was normalized relative to that of an internal control (OsRAD6). The averages of three independent assays are shown. The primers and probes for each gene are listed in Table 1.

\section{Results}

\subsection{Changes in Surface and Internal Structures during Development}

To determine the morphological changes that occur throughout rice leaf development, we separated mature and immature leaves from wild-type seedlings at 15 days after sowing (DAS) to examine the surface and internal structures of rice leaves (Figure 1(A) and Figure 1(B)). We used a plastochron numbering system to represent different stages of leaves, where P1 represents the youngest primordium, P2 the next youngest, etc. [14]. Wildtype seedlings at 15 DAS contained eight leaves, P1-P8, corresponding to the eighth to first leaves, respectively. The second (P7) to fourth (P5) leaves showed obvious differentiation between the leaf blade and sheath disrupted by a ligule and auricle (Figure 1(B)). The boundary of leaf blade and sheath on the fifth (P4) leaf was also recognized at the basalmost part of the P4 leaf primordium. To understand the variation of surface structure of leaves, P1-P6 leaf primordia were examined by scanning electron microscopy (SEM) (Figure 2). SEM images revealed that the surfaces of shoot apex (SA) and P1 and P2 leaf primordia were covered with undifferentiated epidermal cells without any fine structure (Figure 2(A)). The epidermal structure of P3 leaf primordium was similar to that of P2, but trichome initiation was observed on the epidermal cells at the distal part of the P3 primordium (Figure 2(B)).

As the P4 leaf primordium showed quite different epidermal structures along the proximal-distal axis, we examined the surface at five different parts of P4 (Figures 2(C)-(G)). At the distal-most part, fully differentiated trichomes, prickles, epidermal papillae, and stomata cells were found on the surface (Figure 2(C)). This structure was also observed on the middle part of the leaf blade (Figure 2D)). In contrast, all of these epidermal characters were absent on the basal part of the leaf blade (Figure 2(E)) and the sheath (Figure 2(G)) of P4, including the boundary region of the leaf blade and the sheath (Figure 2(F)). The epidermal features of P5 and P6 leaves in most parts were similar to those of the distal part of the P4 leaf; i.e., mature differentiated cells with

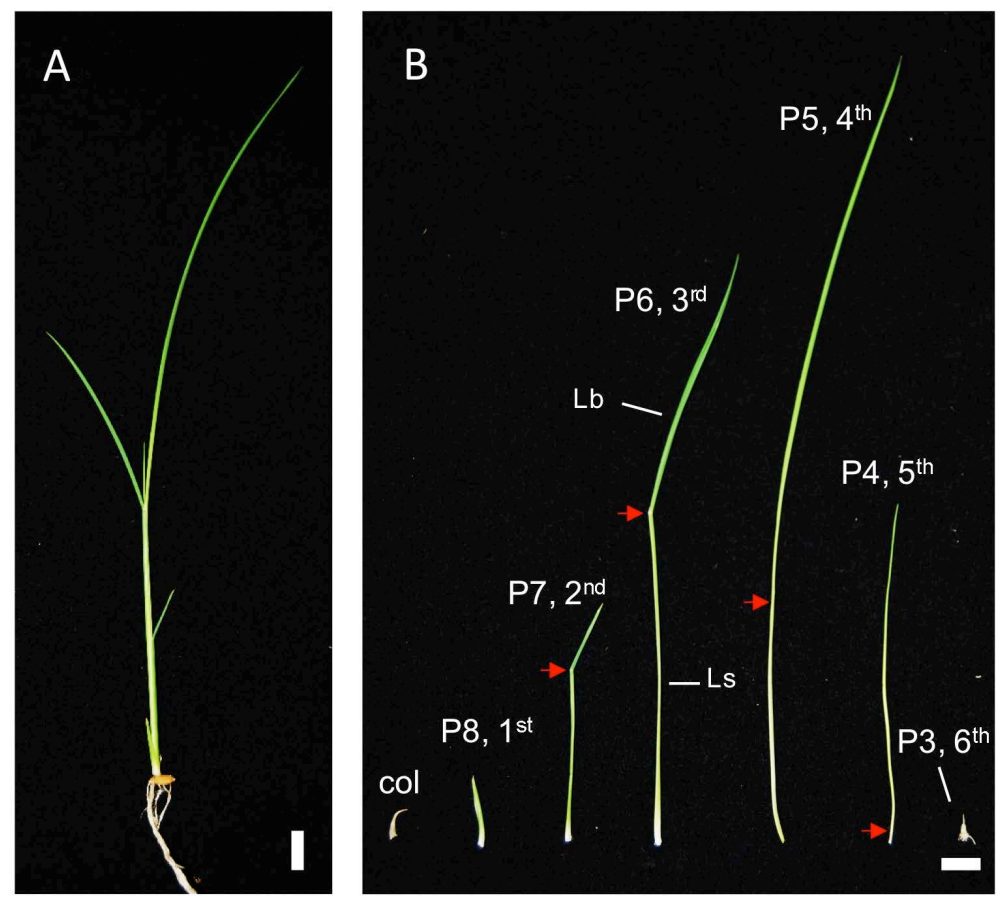

Figure 1. Wild-type seedling and stages of the leaves. A Wild-type seedling at 15 days after sowing (DAS). B The separated leaves and primordia of wildtype seedling of (A). The leaf number and plastochron number of each leaf are labeled. Red arrows indicate the boundary between the leaf blade and sheath. col, coleoptile; Lb, leaf blade; Ls, leaf sheath. Scale bar $=1 \mathrm{~cm}$. 

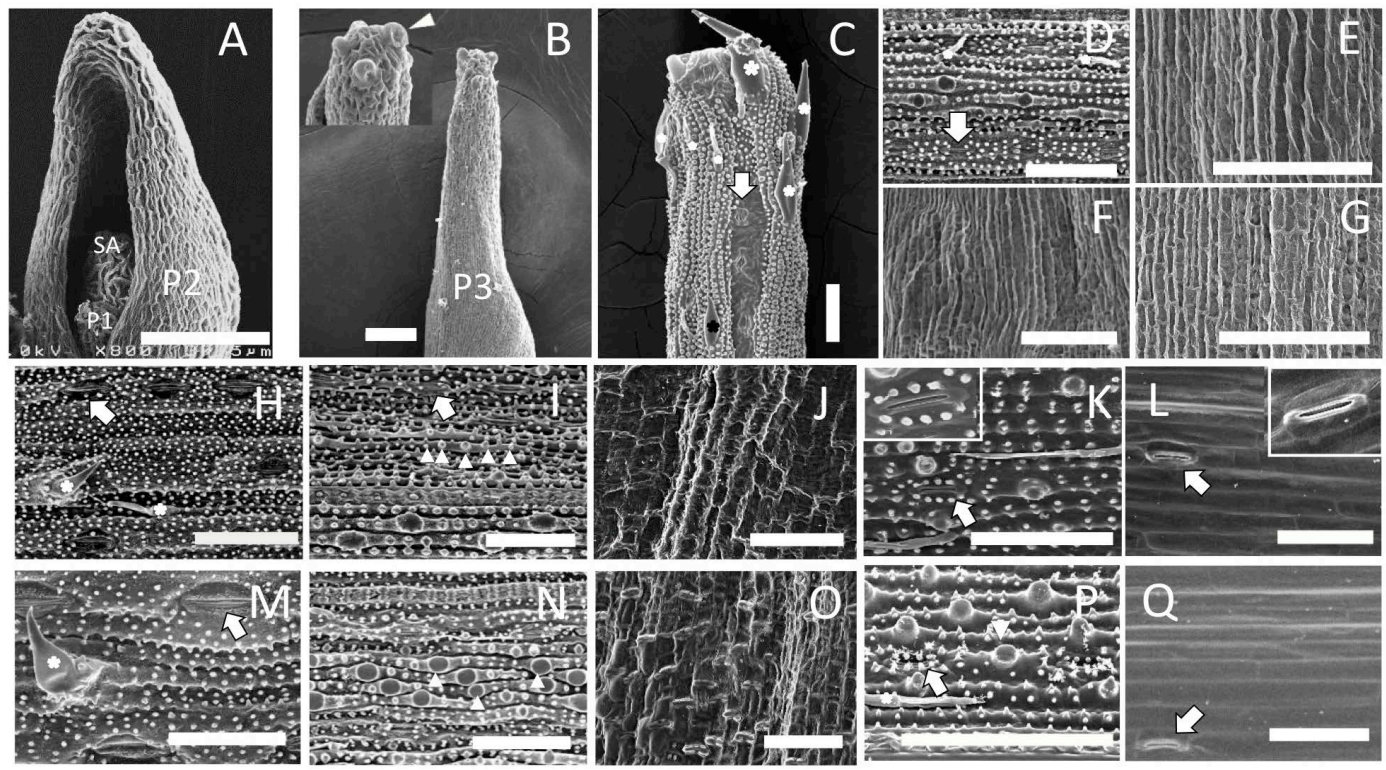

Figure 2. Surface structure of wild-type leaves at various stages. Scanning electron microscopic images of the epidermal structure of P1 to P6 leaves at 15 DAS are shown. (A) Shoot apex (SA), P1 and P2 leaf primordia. (B) P3 leaf primordium. Inset: high-magnification view of P3 leaf tip. Initiation of trichomes (arrowhead) was observed. (C) Distalmost part of the P4 leaf blade. (D) Middle part of the P4 leaf blade. (E) Basal part of the P4 leaf blade. (F) The boundary of the leaf blade and sheath. (G) P4 leaf sheath. (H) Adaxial side of the P5 leaf blade. (I) Abaxial side of the P5 leaf blade. (J) Boundary of the leaf blade and sheath. (K) Abaxial side of the P5 leaf sheath. (L) Adaxial side of the P5 leaf sheath. (M) Adaxial side of the P6 leaf blade. (N) Abaxial side of the P6 leaf blade. (O) Boundary of the leaf blade and sheath. (P) Abaxial side of the P6 leaf sheath. (Q) Adaxial side of the P6 sheath. Asterisks, arrowheads, and arrows indicate trichomes, papillae, and stomata, respectively. Scale bar in $A=37.5 \mu \mathrm{m}$, in $B-Q=50 \mu \mathrm{m}$.

Table 1. List of primer and probe sequences used in real-time PCR analysis.

\begin{tabular}{|c|c|c|c|}
\hline Gene & Forward primer (5'-3') & Reverse primer (5'-3') & Probe (5'-3') \\
\hline OsRAD6 & CGCACGACAACAACATCATG & TCCCACGGCGTGTCATC & $\begin{array}{l}\text { TCTGGAACGCCGTCA } \\
\text { TATTCGGACC }\end{array}$ \\
\hline OsCDKB2 & GGAATCCCTCGAAAGTGTCTGA & TCGTACTGCAGCATTTTCTCAAG & $\begin{array}{l}\text { TCCATGGTCTCGACGC } \\
\text { TGATGCTC }\end{array}$ \\
\hline OsRBCS2 & ATGCAGGTGTGGCCGATT & CAGGGCACCCACTTGGAA & $\begin{array}{l}\text { CGAGACCCTCTCTT } \\
\text { ACCTGCCACCG }\end{array}$ \\
\hline OsTCP1 & GGAGGTAGCACAAGTGCACT & CCAATGACATGCGCAGCAGCAG & $\begin{array}{l}\text { CGGTTGGTTGGTTGG } \\
\text { TTGGTTTTCCATCG- }\end{array}$ \\
\hline OsTCP12 & GAGCGCCAGCGACTCGTA & $\begin{array}{l}\text { TTAAAGAAGAACAGATCAAAACCA } \\
\text { GAGA }\end{array}$ & TCCGGTGTGTGCCCCGCATT \\
\hline OsGRF10 & СССАТСТТСТТТСТТСАТТССТСТТ & СТТСТССТСАТССАТТСТGАСААСТ & $\begin{array}{l}\text { CCACCAAGAACCCC } \\
\text { AAACCTTACCTCC }\end{array}$ \\
\hline Pri-miR396c & GCTTGCAGCCATAAAGCTCTTC-3’ & TGCCATCTGCCTCTCTCTTGA & $\begin{array}{l}\text { CCTCTCTCTTTCTA } \\
\text { CGGCTGTGGAGCTGA }\end{array}$ \\
\hline
\end{tabular}

papillae and two types of trichome (unicellular and bicellular), and stomata cells were observed on the adaxial (Figure 2(H) and Figure 2(M)) and abaxial sides of the leaf blade (Figure 2(I) and Figure 2(N)) and the abaxial side of the sheath (Figure 2(K) and Figure 2(P)). In contrast, the adaxial side of P5 and P6 leaf sheaths had no papillae or trichomes (Figure 2(L) and Figure 2(Q)). However, fully developed stomata were present and the epidermal cells were elongated, indicating that the cells of the adaxial epidermis of P5 and P6 leaf sheaths were mature. The epidermis of the boundary of both leaf blade and sheath of P5 and P6 showed rectangle epidermal cells without any differentiated cells (Figure 2(J) and Figure 2(O)), indicating that the boundary of the 
leaf blade and sheath has different properties from those of the leaf blade and leaf sheath.

Examination of surface structures indicated that cellular differentiation of the leaf epidermis started at the tip of P3 and proceeded to the middle part of P4, but did not reach the basal part of P4. Next, we examined the internal structure of P1-P6 leaf primordia on paraffin- and plastic-embedded sections (Figure 3). Examination of shoot apex cross-sections indicated that P1 and P2 primordia consisted of small cytoplasm-rich cells, and no tissue differentiation was observed (Figure 3(A)). Most of the cells in P3 were similar to those of P1 and P2, but immature vascular bundles were recognized in the basal and apical parts of P3 (Figure 3(B)). Cross-sections from the top (Figure 3(F)) and middle (Figure 3(E)) regions of the P4 leaf blade showed similar internal structure. Mesophyll cells, phloem cells, xylem cells, bundle sheath cells, and sclerenchymatous fiber cells were differentiated in these regions. Bulliform cells were present on the adaxial side of leaf blade at the middle parts (Figure 3(E)), although they were not obvious in the top of the P4 leaf blade (Figure 3(F)). In addition, the cytoplasm of epidermal cells in the top (Figure 3(F)) and middle (Figure 3(E)) regions of the P4 leaf blade were not strongly stained by hematoxylin, indicating that the epidermal cells in these regions were vacuolated. The internal structures of the basal part of the leaf blade (Figure 3(D)) and leaf sheath (Figure 3(C)) were different from those at the top and middle parts of P4. Most of the epidermal cells and mesophyll cells were rich in cy-
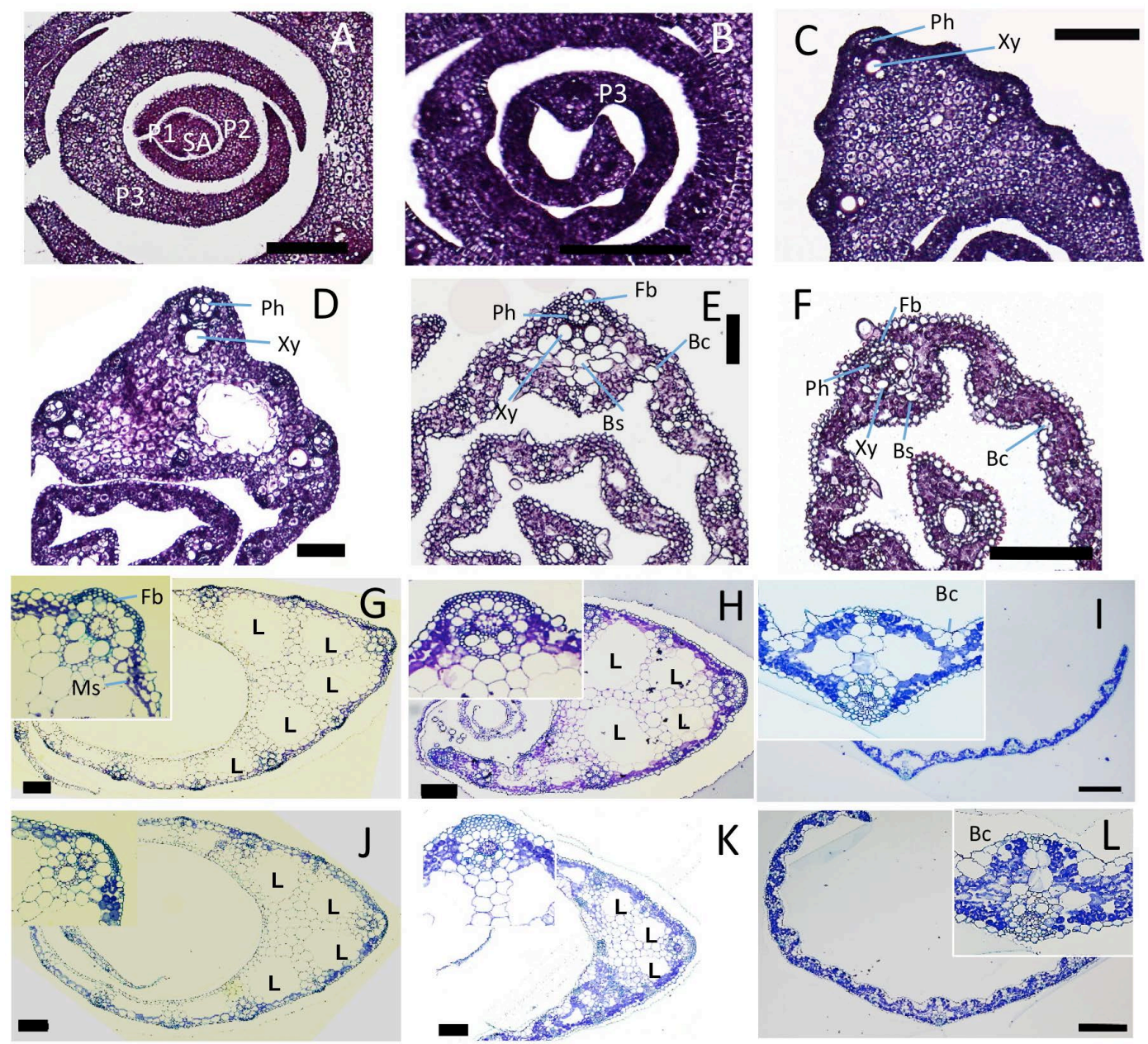

Figure 3. Internal structure of wild-type leaves at various stages. Transverse sections of P1 to P6 leaf primordia at 15 DAS are shown. Insets in G-I show high-magnification views of large vascular tissue. (A) P1, P2, and P3 leaf primordia and shoot apex (SA). (B) Apical part of P3. (C) Leaf sheath of P4. (D) Basal part of P4 leaf blade. (E) Middle part of P4 leaf blade. (F) Apical part of P4 leaf blade. (G) Leaf sheath of P5. (H) Boundary of leaf sheath and blade of P5. (I) Leaf blade of P5. (J) Leaf sheath of P6. (K) Boundary of leaf sheath and blade of P6. (L) Leaf sheath of P6. Bc, bulliform cells; Fb, fiber cells; Ph, phloem; Xy, xylem; Bs, bundle sheath; L, lacuna. Scale bars in $(A-H)$ and $(J)=100 \mu \mathrm{m}$, in $(\mathrm{I}),(\mathrm{K})$, and $(\mathrm{L})=250 \mu \mathrm{m}$. 
toplasm, although xylem and phloem cells were obvious. In particular, lacunae (air spaces) observed in the mature leaf sheath (Figure 3(G) and Figure 3(J)) could not be seen (Figure 3(C)).

Transverse sections of P5 and P6 leaves showed similar anatomical features. Mesophyll cells, all of the components of the vascular bundle, and sclerenchymatous fiber cells were fully differentiated along the leaf axis (Figures 3(G)-(L)). Bulliform cells were present on the adaxial side of the leaf blade (Figure 3(I) and Figure $3(\mathrm{~L}))$.

Observation of the surface and internal structure of leaf primordia during development indicated that most of the cells of P1 to P3 leaf primordia were in an undifferentiated state, whereas the cells of P5 and P6 were fully differentiated. These observations indicated that P1 to P3 leaf primordia are in the immature phase and P5 and P6 are in the mature phase of leaf development. However, differentiated and undifferentiated cellular characters were observed in the top part and basal part of the P4 leaf, respectively, indicating that a marked developmental transition would occur around the middle part of the P4 leaf, and cellular differentiation proceeded in a basipetal direction.

\subsection{Changes in Cellular Components along the Proximal-distal axis of the P4 Leaf Primordium}

Morphological analysis indicated that the P4 leaf primordium contains a transition region where transformation of immature cellular characters into the mature state occurs. To obtain further evidence of the transition, we examined the cellular components of the P4 leaf, chloroplast and starch accumulation, and lignin deposition of the cell wall of the P4 leaf by histochemical analysis.

\subsubsection{Chloroplast}

The color of the dissected P4 leaf at the apical part was green, whereas the basal part was whitish in color (Figure 1(B)), indicating differences in chloroplast differentiation and accumulation of chlorophyll between apical and basal parts of the leaf. To clarify the pattern of chloroplast differentiation along the proximal-distal axis of the P4 leaf primordium, we examined chlorophyll accumulation in the apical, sub-apical, sub-basal, and basal parts of the P4 leaf blade by fluorescence microscopy. Chloroplast autofluorescence was obvious in the mesophyll cells of the apical and sub-apical parts of the P4 leaf (Figure 4(A) and Figure 4(B)). However, chloroplasts were not discernible in the sub-basal part (Figure 4(C)) and undetectable in the basal part of the P4 leaf (Figure 4(D)).

\subsubsection{Starch}

Starch is a major product of photosynthesis in higher plants. Although starch mostly accumulates in the endosperm during seed maturation in rice, it shows temporary accumulation in the leaves [15]. To determine the pattern of starch accumulation in the P4 leaf primordium, four parts of the P4 leaf primordium were stained with iodine-potassium iodide solution. Numerous starch granules were detected in the mesophyll cells in the basal part of the P4 leaf blade (Figure 4(H)), but fewer starch granules were observed in the apical and sub-basal parts (Figures 4(E)-(G)). The mature leaf sheath function as a sink of photosynthetic product, and starch is synthesized from carbohydrates derived from other photosynthetic tissues in the leaf sheath [12]. Therefore, our results indicate that the regional distribution of sink and source of photosynthetic product was established in P4, and the sink part is independent of differentiation of the leaf blade and sheath in P4.

\subsubsection{Lignified Cell Walls}

Lignin is a phenolic polymer that provides rigidity to cell walls by crosslinking with polysaccharides. Lignin is mainly deposited in supporting and conducting tissues, such as the sclerenchyma and vascular tissues in mature tissue [16]-[19]. The results of P4 leaf primordium morphological analysis indicated that the apical part of P4 exhibited mature cellular characters, while the basal part showed immature characters. To determine whether cell wall composition is also different between apical and basal parts, we investigated the pattern of the lignified cell walls. Red staining revealed accumulation of lignin in the epidermal cells, sclerenchyma, and xylem tissues in the apical and sub-apical parts of P4 leaves (Figure 4(I) and Figure 4(J)). However, staining in the epidermal cells was not obvious in the sub-basal and basal parts of P4 leaves (Figure 4(K) and Figure 4(L)). These results suggest that not only the accumulation of cellular components but also the deposition of secondary cell wall was differentially regulated in $\mathrm{P} 4$ leaves along the apical-basal axis. 

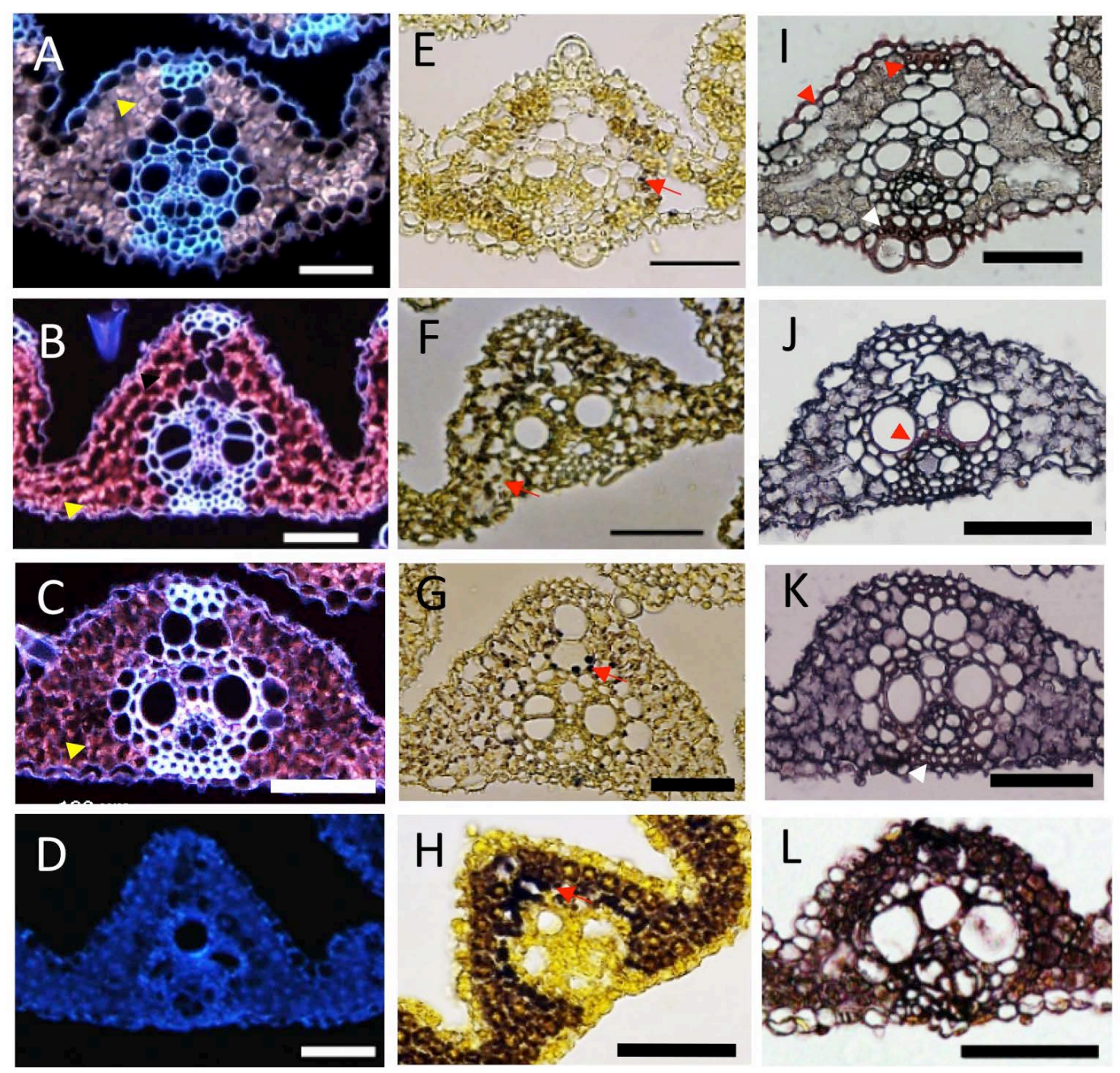

Figure 4. Histochemical analysis of P4 leaf primordium along the proximal-distal axis. Four parts of P4 leaf blade along the proximal-distal axis; apical (A, E, I), sub-apical (B, F, J), sub-basal (C, G, K), and basal (D, $\mathrm{H}, \mathrm{L}$ ) parts are shown. A-D Autofluorescence of chloroplasts. The arrowhead indicates chloroplasts. E-H Starch accumulation. The arrow indicates starch granules. I-L Lignified cell. The arrowhead indicates lignified tissues. Scale bars $=100 \mu \mathrm{m}$.

\subsection{Screening of Marker Genes Showing Dynamic Expression Pattern in P4 Leaf Primordium along the Proximal-Distal Axis}

To obtain a further understanding of the developmental transition and gradient along the leaf axis of P4 leaf primordia at the molecular level, we first searched for marker genes reflecting the transition and gradient. For screening, we divided P4 leaves into four parts along the longitudinal axis; i.e., the apical leaf blade, the middle leaf blade, the basal leaf blade, and the leaf sheath (Figure 5(A)). RNA extracted from each part of P4 leaves was subjected to RT-PCR analysis. We first examined the expression patterns of two genes related to physiological events in the leaves; i.e., OsCDKB2 that encodes a B-type cyclin-dependent kinase with a role in cell cycle progression [1] [2] and OsRBCS2 encoding one of the small subunits of RubisCO (ribulose 1, 5-bisphosphate carboxylase/oxygenase) that accumulates in photosynthetic tissue [20]-[22]. Higher levels of OsCDKB2 and OsRBCS2 expression would represent activation of cell division and photosynthesis, respectively. OsCDKB2 expression was higher in the basal leaf blade and leaf sheath, but was absent in the apical and middle leaf blade regions (Figure 5(B)). The expression level of OsRBCS2 was highest in the apical and middle leaf blade and lower in the basal leaf blade and leaf sheath (Figure 5(B)). The expression patterns of the two genes could account for the physiological changes predicted by our morphological and histochemical analyses. 
Next, we examined the expression patterns of TCP and GRF genes as potential marker genes for developmental changes in the leaf, because some TCP and GRF genes are known to be involved in leaf development in rice and Arabidopsis. Among the 26 OsTCP genes [23] and 12 OsGRF genes [24] identified in the rice genome, we chose OsTCP1, OsTCP12, and OsGRF10 for RT-PCR analysis. Both of OsTCP1 and OsGRF10 were highly expressed in the basal leaf blade and leaf sheath (Figure 5(B)). OsTCP12 showed an intermediate expression level around the middle and basal leaf blade, including the leaf sheath (Figure 5(B)). In addition to TCP and GRF genes, one of the miR396 genes, pri-miR396c, was used. Pri-miR396c was strongly expressed in the basal and apical leaf blade as well as in the leaf sheath (Figure 5(B)). These six genes showing differential expression along the proximal-distal axis of the P4 leaf were used in further experiments.

\subsection{Expression Changes of Six Marker Genes in Wild-Type P4 Leaf Primordium}

To determine the expression dynamics of six marker genes more accurately along the longitudinal axis of P4 leaves, we examined the expression patterns of these genes by real-time PCR in eight parts from the top (P4-1) to the bottom (P4-8) (Figure 6(A)). In addition, we also examined the expression of these genes in three different stages; i.e., the early, middle, and late stages of P4. First, to confirm the stages of these P4 leaves, the shoot apex of the dissected sample was examined in paraffin sections (Figures 6(B)-(D)). The shoot apex of the early P4 stage showed that P1 leaf primordium had just emerged from the lateral region of the shoot apical meristem (Figure 6(B)). With progression of development, enlarged P1 leaf primordium was observed on the shoot apex (Figure 6(C) and Figure 6(D)). Thus, the three samples of P4 leaf primordia used in this analysis reflect the developmental progression of $\mathrm{P} 1$ and possibly other leaf primordia.

Overall, the expression patterns of OsCDKB2, OsGRF10, and OsTCP1 showed similar trends. The expression levels of these genes from P4-1 to P4-5 in three developmental stages were low (Figures 6(E)-(G)). Particularly, the expression pattern of OsGRF10 was almost identical to that of OsCDKB2, indicating that OsGRF10 is closely associated with cell division in the regions of the leaf positive for its expression. The expression pattern of OsTCP1 differed slightly from those of OsCDKB2 and OsGRF10, in that OsTCP1 was still expressed around

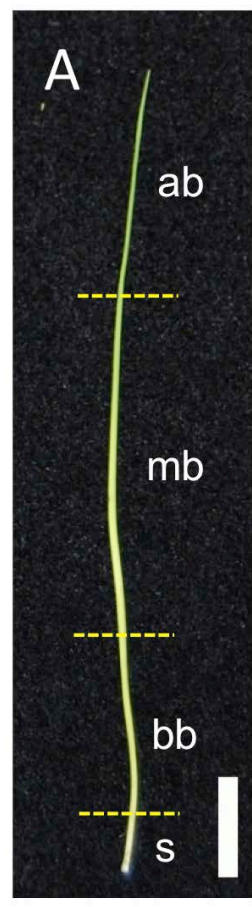

\section{B}
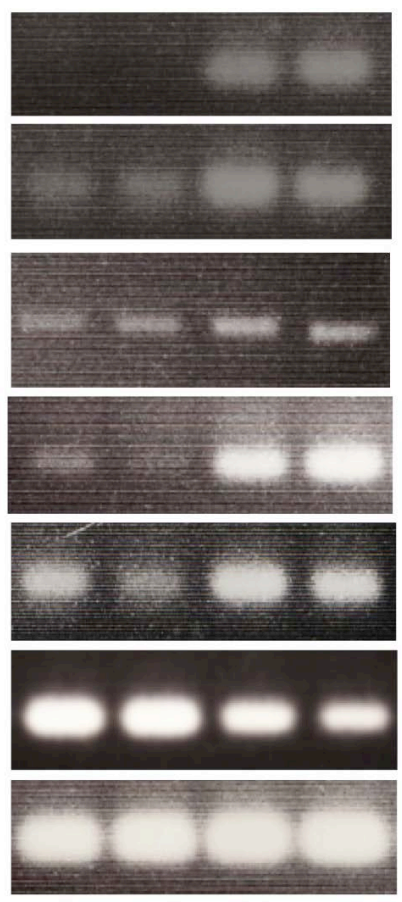

ab $\mathrm{mb} \quad \mathrm{bb} \quad \mathrm{s}$

\section{OsCDKB2}

OsTCP1

OsTCP12

OsGRF10

Pri-miR396c

OsRBCS2

UBQ5

Figure 5. Expression of six marker genes in wild-type P4 leaf primordium. (A) Four segments of P4 leaf primordium along the proximal-distal axis. (B) Semi-quantitative RT-PCR analysis of six marker genes and an internal control, UBQ5. ab, apical leaf blade. mb, middle leaf blade. bb, basal leaf blade. s, leaf sheath. Scale bar $\mathrm{A}=1 \mathrm{~cm}$. 
the middle part of the P4 leaf (P4-6) (Figure 6(F)), while both OsCDKB2 and OsGRF10 were completely downregulated in this region (Figure 6(E) and Figure 6(G)). The expression pattern of OsTCP12 was unique. Two peaks of expression were observed at the basal and middle parts of the P4 leaf in all developmental stages (Figure 6(H)). One peak was observed around the middle part of P4, and the peak shifted toward the basal parts as development progressed. Another peak was seen at the basalmost part in the three stages. Pri-miR396c was expressed in the basal part of the P4 leaf (Figure 6(I)), but its expression pattern was also different from those of OsCDKB2 and OsGRF10. The expression pattern of pri-miR396c was characterized by the highest level of expression not in the basalmost region but in P4-7 (Figure 6(I)), although the expression pattern at the late stage was similar to that of OsTCP1. The expression pattern of OsRBCS2 was completely different from those of the other genes examined (Figure 6(J)). The expression level of OsRBCS2 was highest at the apical part of P4 at the early stage of development, while the peak was not obvious in the middle and late stages (Figure 6(J)). OsRBCS2 expression was not detected at the basal part of the P4 leaf at any stage of leaf development.

Real-time PCR experiments showed that the expression peaks of all marker genes shifted toward the basal part of the P4 leaf, indicating that these genes are influenced by developmental and/or physiological events that proceed in the basipetal direction. As leaf maturation is known to advance in a basipetal manner, these six marker genes would be suitable to monitor developmental transition along the apical-basal axis of P4 leaves.

\subsection{Gene Expression Analysis in Various Morphogenetic Mutants}

Many genes affecting leaf morphogenesis have been identified in rice. In most cases, although the morphological differences between mature wild-type and mutant leaves is obvious, the changes occurring during leaf development leading to the final morphology of the mutant have not been clarified. To understand the relationship
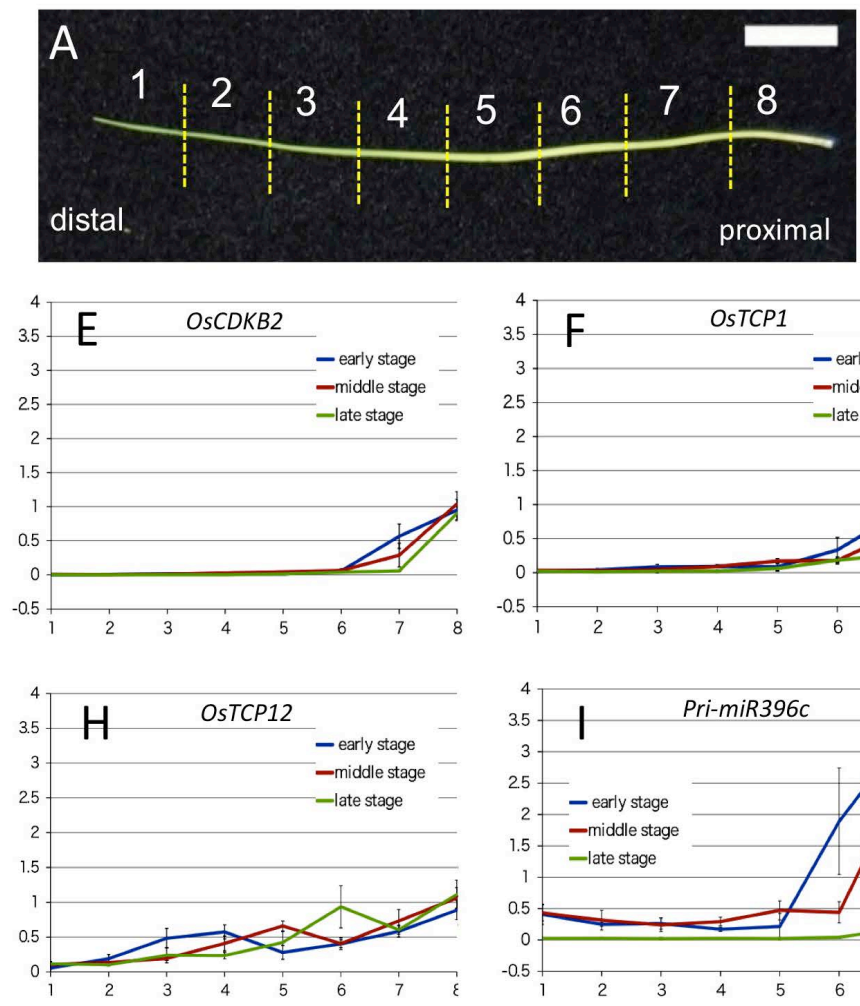
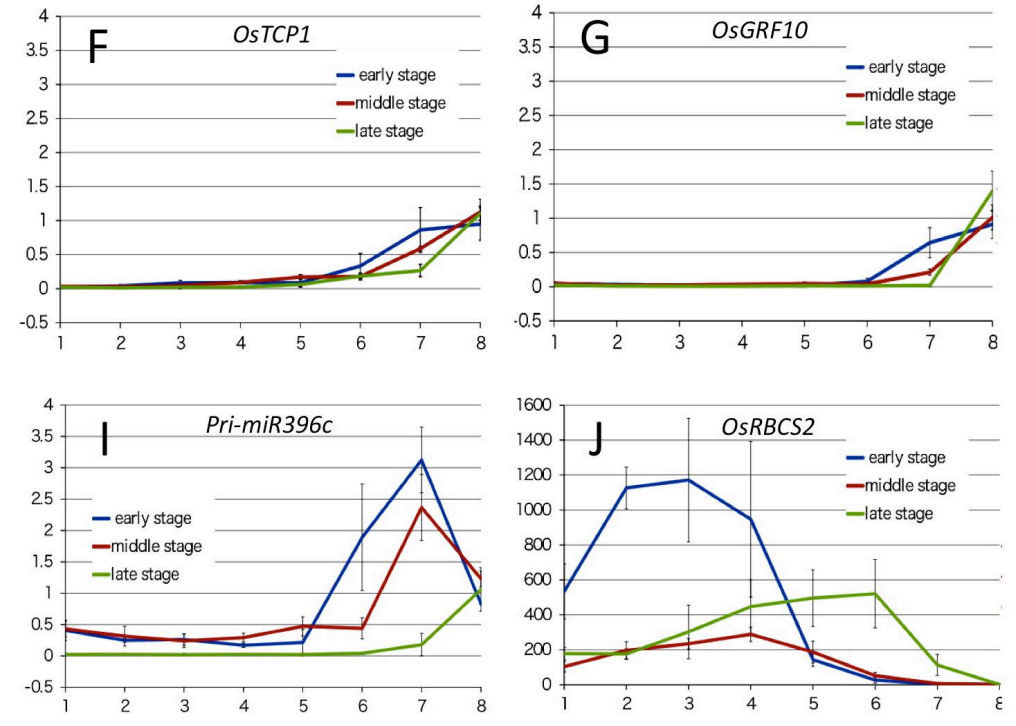

Figure 6. Real-time PCR analysis of six marker genes along the longitudinal axis of the P4 leaf primordium at different developmental stages. (A) Eight segments of P4 leaf primordium along the proximal-distal axis; (B) Shoot apex of wild type in the early stage. (C) Shoot apex of wild type in the middle stage; (D) Shoot apex of wild type in the late stage; (E) OsCDKB2; (F) OsTCP1; (G) OsGRF10; (H) OsTCP12. (I) Pri-miR396c. (J) OsRBCS2. The numbers along the horizontal axis indicate the position of the P4 leaf along the longitudinal axis as represented in (A). Expression level was normalized relative to that of an internal control (OsRAD6). SA, shoot apex. Scale bars $\mathrm{A}=1 \mathrm{~cm}, \mathrm{~B}-\mathrm{D}=50 \mu \mathrm{m}$. 
between mutant phenotype and the process of leaf development, we performed expression analysis of five genes-OsCDKB2, OsGRF10, OsTCP1, OsTCP12, and pri-miR396c-in the P4 leaf primordium of six known mutants showing defects in leaf morphogenesis. Expression analysis of OsRBCS2 was not performed in this analysis, because the expression level of OsRBCS2 was too different from the other five genes to compare expression levels, and the shift in expression level among the three stages was not consistent with developmental stages of the P4 leaf.

\subsubsection{Liguleless $(\mathrm{lg})$}

The liguleless mutant completely lacks ligules and lamina joints (Figure 7(A)). The causal gene encodes an SBP (SQUAMOSA promoter Binding Protein) domain-containing protein and is specifically expressed in the ligule, lamina joint, and the base of the leaf sheath of the leaf [25]. Based on the stage of P1 in the shoot apex of the $l g$ mutant, the stage of P4 sampled here was predicted to be the middle stage (Figure 7(G)). The expression patterns of the five marker genes in the $l g$ mutant (Figure 7(P)) were almost identical to those of wild-type controls in the middle stage (Figure $7(\mathrm{~N})$ ). These observations indicated that the $L G$ gene is not involved in the process of leaf development other than in ligule and lamina joint differentiation along the apical-basal direction.

\subsubsection{Drooping Leaf $(d l)$}

The midrib is a structure that is formed along the midvein of the leaf blade to maintain an upright angle of the leaf. The $d l$ mutants show a defect of midrib formation that causes a drooping leaf phenotype (Figure 7(B)). $D L$ encodes a member of the YABBY family of transcriptional regulators, which functions in cell proliferation in the central domain of the leaf [26] [27]. Based on the stage of P1 in the shoot apex of the $d l$ mutant, the stage of P4 sampled here was predicted as the middle stage (Figure $7(\mathrm{H})$ ). The expression patterns of OsCDKB2, OsGRF10, OsTCP1, and pri-miR396c in $d l$ mutants were similar to those of the wild-type controls in the middle stage (Figure 7(N) and Figure 7(Q)). However, the expression level of OsTCP12 was elevated in the middle part of the leaf. The position of the expression peak of OsTCP12 relative to the leaf axis was unaffected.

\subsection{3. dwarf61 (d61)}

The $d 61$ mutant showed a dwarf phenotype caused by inhibited elongation of the culm, and also showed reduced leaf bending at the lamina joint and shorter leaf sheath (Figure 7(C)). The $d 61$ mutant has a mutation in the OsBRI1 gene, which encodes a brassinosteroid (BR) receptor kinase [28]. Based on the stage of P1 in the shoot apex of the $d 61$ mutant, the stage of $\mathrm{P} 4$ sampled here was predicted to be the middle stage (Figure 7(I)). The expression patterns of OsCDKB2, OsGRF10, OsTCP1, and pri-miR396c in the $d 61$ mutant were similar to those in wild-type controls in the middle stage, although the level of the OsTCP12 expression was elevated in the apical and middle parts of the leaf (Figure 7(N) and Figure 7(R)).

\subsection{4. dwarf1 (d1)}

The $d 1$ mutant has a mutation in the gene encoding the $\alpha$-subunit of the heterotrimeric $G$ protein, which affects plant height and seed size [29]. The leaf length of the $d 1$ mutant is shortened compared with the wild-type (Figure 7(D)). Based on the stage of P1 in the shoot apex, the stage of P4 in $d 1$ sampled here was predicted to be the early stage (Figure 7(J)). Despite this early stage, the expression patterns of OsCDKB2, OsGRF10, and OsTCP1 were similar to those of wild-type controls in the middle stage (Figure 7(N) and Figure 7(S)). In addition, the expression patterns of pri-miR396c and OsTCP12 were very different from those of the wild-type. The expression peak of OsTCP12 was detected at P4-4 (Figure 7(S)), in contrast to the peak seen at the early stage in wild-type (Figure 7(M)), although expression levels in the basal part were higher than those in the wild-type controls. The expression pattern of pri-miR396c was similar to that in the late stage of wild-type controls (Figure 7(O)). Thus, the expression patterns of multiple genes in the P4 leaves of $d 1$ were markedly disturbed.

\subsection{5. dwarf18 (d18)}

The $d 18$ mutant shows a dwarf phenotype that is caused by a defect in the gibberellin (GA) biosynthetic gene OsGA3ox2 [30] (Figure 7(E)). As leaf elongation of $d 18$ is severely affected, we sampled four rather than eight parts of the $d 18 \mathrm{P} 4$ leaf. Based on the stage of $\mathrm{P} 1$ in the shoot apex, the stage of P4 in $d 18$ was predicted to be the early stage (Figure 7(K)). Although, it is difficult to compare gene expression patterns between four parts of $d 18$ and eight parts of wild-type controls, the changes in expression of OsCDKB2, OsGRF10, OsTCP1, and 

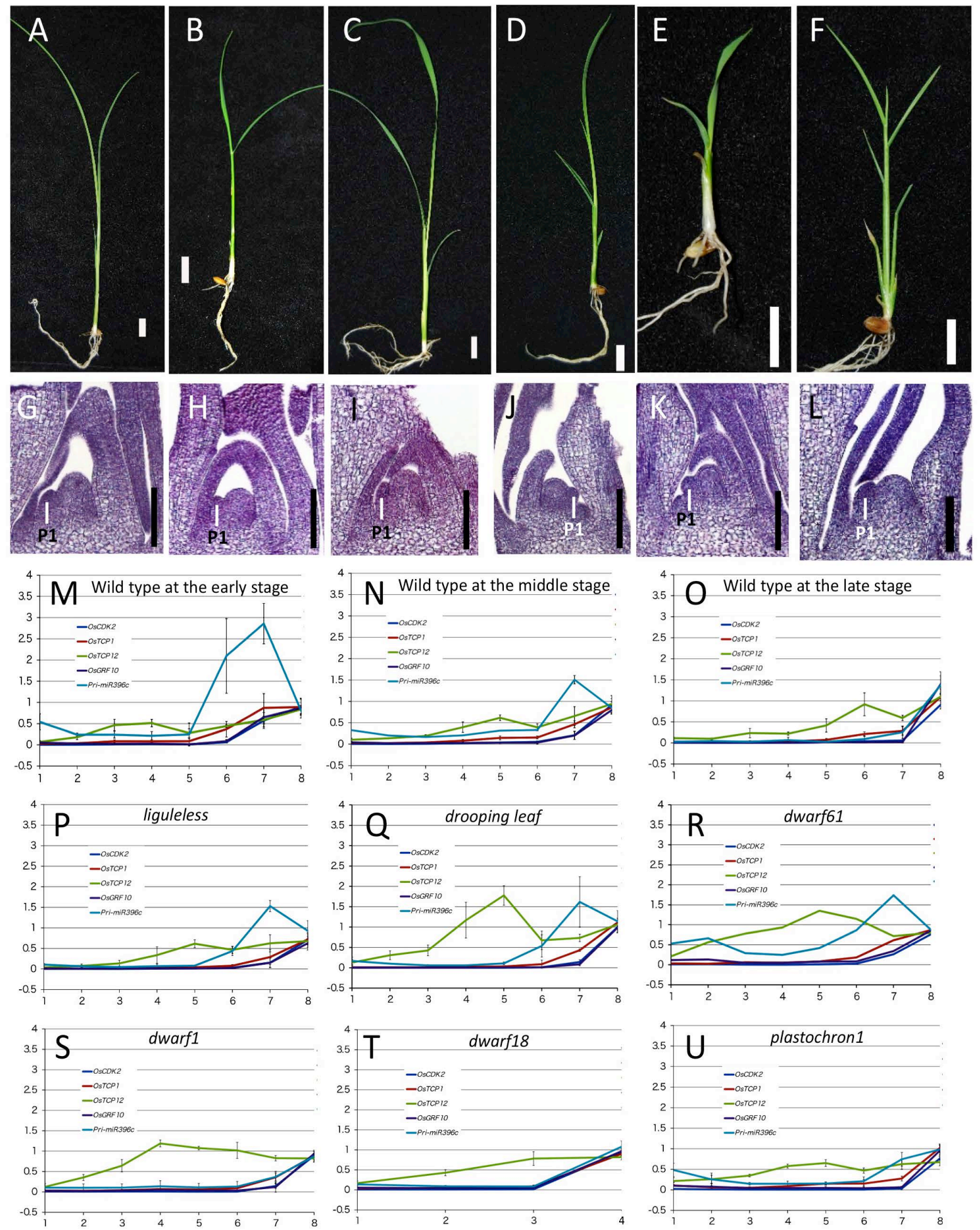

Figure 7. Phenotypes of leaf morphogenetic mutants and expression patterns of five marker genes. (A-F) Seedling phenotype. (G-L) Longitudinal section of shoot apex. (M-U) Expression patterns of five marker genes. (A, G, P) lg. (B, H, Q) dl. $(\mathrm{C}, \mathrm{I}, \mathrm{R}) d 61$. (D, J, S) $d 1$. (E, K, T) $d 18$. (F, L, U) pla1-4. (M) Wild-type in at the early stage. (N) Wild-type in at the middle stage. (O) Wild-type in at the late stage. The numbers along the horizontal axis indicate the position of the P4 leaf along the longitudinal axis as represented by Figure 5(A). Expression level was normalized relative to that of an internal control (OsRAD6). SA, shoot apex. Scale bars $(\mathrm{A}-\mathrm{F})=1 \mathrm{~cm},(\mathrm{G}-\mathrm{L})=50 \mu \mathrm{m}$. 
pri-miR396c along the leaf axis were similar (Figure $7(\mathrm{~T})$ ). This pattern suggested that the P4 leaf of $d 18$ showed a similar expression profile to the wild-type, despite the markedly reduced length of $\mathrm{P} 4$ in the mutant (Figure 7(N)).

\subsubsection{Plastochron1 (pla1)}

The characteristic phenotype of the pla1 mutant is rapid production of short leaves (Figure 7(F)). PLA1 encodes a member of the cytochrome P450 family, CYP78A11, the substrate of which is unknown [31]. It was suggested previously that the shortened pla1 leaf is due to precocious maturation of leaf primordia [32]. Based on the stage of P1 in the shoot apex, the stage of P4 leaf primordium of pla1 was predicted to be the middle stage (Figure 7(L)). However, expression patterns of OsCDKB2, OsGRF10, and OsTCP1 were similar to the late stage of the wild-type control (Figure 7(O) and Figure 7(U)). The expression of pri-miR396c showed an intermediate pattern between middle and late stages, whereas the expression peak of OsTCP12 was the same as that of wild-type controls in the middle stage (Figure 7(N), Figure 7(O) and Figure 7(U)). Thus, pla1 affects the relative positions of the marker gene expression peaks.

The results indicated that marker gene expression patterns were affected in $d l, d 61, d 1$, and pla1 mutants, but not in the $\lg$ mutant. Although we could not determine conclusively whether marker gene expression was altered in $d 18$, the trend of the expression profile was globally conserved compared to that of the wild-type controls. In addition, the results indicated that alteration of marker gene expression patterns differed among the mutants, and the sensitivity of pri-miR396c and OsTCP12 expression changes was high, while that of OsCDKB2, OsGRF10, and OsTCP1 was low. Accordingly, our expression analysis using five marker genes would be useful to characterize developmental features of mutants and to understand the genetic and physiological alterations that could not be determined from the morphological phenotype.

\section{Discussion}

\subsection{Developmental Transition during Leaf Development in Rice}

Leaf differentiation proceeds sequentially in a basipetal manner in grass leaves. However, the timing and relative position of the transition from cell proliferation to cell differentiation is variable among species. Therefore, we examined various characters of the leaves at all stages during development in rice. Our morphological and histochemical analyses indicated that most parts of the P1 to P3 leaf primordium had immature characters, while P5 and P6 leaves were mature. On the other hand, our results indicated that the dynamic transitions of various aspects of developmental and physiological traits occur at the basal part of the P4 leaf blade. The traits included the epidermal structure (papillae, trichomes, and guard cells) (Figure 2), internal structure (cell type differentiation, cell components of the vascular bundle, and density of cytoplasm) (Figure 3), and cellular components (chloroplasts, starch, and lignified cell walls) (Figure 4). Although the transitions of all traits do not occur simultaneously, our analyses indicated that most of the transitions occur in the restricted part of the P4 leaf along the proximal-distal axis. In addition, the transition was shown to be determined independently of leaf blade and leaf sheath differentiation. Therefore, our analysis suggested that the P4 leaf primordium is the optimal stage of leaf development to uncover the genetic mechanism underlying developmental and physiological transitions during leaf development.

\subsection{Expression Patterns of Marker Genes and Their Possible Functions in Leaf Development}

We selected marker genes based on their expression changes along the apical-basal axis of the P4 leaf. Unfortunately, with the exception of OsCDKB2 and OsRBCS2, the biological functions of most of these marker genes have not been elucidated. OsCDKB2 encodes a B-type cyclin-dependent kinase that is required for the transition from $\mathrm{G}_{2}$ to $\mathrm{M}$ (mitosis) phases of the cell cycle [1] [2]. Thus, tissues expressing OsCDKB2 reflect sites of active cell division. Real-time PCR experiments using wild-type P4 leaves at three stages indicated an expression peak of OsCDKB2 in the basalmost part of P4. This was consistent with the observation that the cell division zone was located at the base and the cell maturation progress in a basipetal manner in grass species. OsRBCS2 is a member of the RubisCO small subunit multigene family in rice. It has been reported that OsRBCS2 to OsRBCS5 are highly expressed in the rice leaf blade, and there is a positive correlation between the expression level of RBCS and maximal RubisCO contents [20]-[22]. Thus, the sites of OsRBCS2 expression are considered to be 
regions of active photosynthesis. Although the expression peak of OsRBCS2 shifted from the apical to the basal part with progression of leaf development, the peak of expression was observed in the early stage with the lowest level in the middle stage (Figure 6(J)). This was not consistent with the prediction that photosynthetic activity would change sequentially among the three stages. Although we could not determine why the expression level did not change gradually among the stages, it is possible that the OsRBCS2 expression level is sensitive to environmental cues that we could not predict.

The TCP transcription factor genes are known to be involved in multiple developmental pathways, and some have been shown to play key roles in the coordination of cell proliferation and cell differentiation in leaves [3]. TCP proteins are generally classified into two main classes based on differences in their conserved domains; i.e., class I and class II. Class I TCP proteins have been suggested to promote plant growth and cell proliferation, while class II proteins act as repressors of cell proliferation. OsTCP1 (also has known PCF5) belongs to class II and is involved in lateral organ development [33]. Although its exact function has not been elucidated, OsTCP1 may act as a negative regulator of cell proliferation during leaf development. The expression pattern of OsTCP1 is very similar to that of $O s C D K B 2$, but a low level of expression remained in regions where OsCDKB2 expression was completely down-regulated (e.g., P4-6) (Figure 6(F) and Figure 6(E), respectively). Thus, it is possible that OsTCP1 functions in spatial coordination of cell proliferation by suppressing cell division in the basal part of the leaf. OsTCP12 belongs to the class I TCP genes that support the cell proliferation process in plant growth, although context-dependent effects of some class I TCP genes were reported in Arabidopsis. It has been reported that OsTCP12 (or OsTCP19) is expressed not only in leaves but also in endosperm, roots, and the early panicle [23], and our expression analysis suggested that it was expressed in the P4 leaf primordium with two peaks along the leaf axis - the first peak was seen in the middle part of P4 with the other in the basalmost part (Figure 6(H)). Phylogenetic analysis suggested that the closest homologs of OsTCP12 are TCP14/TCP15 in Arabidopsis [34]. Although developing leaves of tcp14/tcp15 double mutants do not show an obvious phenotype, quantitative imaging analysis and SRDX fusion experiments indicated that TCP14/TCP15 modulate leaf shape by repressing cell proliferation. Interestingly, TCP14 is expressed in young trichomes of developing leaves and plants expressing SRDX-fused TCP14 showed highly branched trichomes, indicating that TCP14 also regulates trichome development [35]. Although it is unclear whether the function of OsTCP12 in rice is similar to that of TCP14 in Arabidopsis, and whether the OsTCP12 is expressed in trichomes, it is possible that the first peak (middle part of P4) of OsTCP12 was involved in epidermal differentiation of leaves. In support of this suggestion, our morphological analysis indicated that the position of the second peak of OsTCP12 expression was close to the boundary of tissue with/without epidermal structures, such as trichomes and papillae. However, expression analysis using various mutants suggested another possible function of OsTCP12, as discussed below.

GRF genes have been shown to play crucial roles in growth and development of leaves by regulating cell proliferation in a redundant manner in Arabidopsis [3]. Twelve GRF genes were identified in the rice genome, most of which were preferentially expressed in young and growing tissues [24]. Although there is no direct evidence that rice GRFs promote cell proliferation in leaves, a double mutant of OsGRF6 and OsGRF10 showed a semidwarf phenotype [36]. Thus, OsGRF10 may positively regulate leaf growth by controlling cell proliferation. In fact, our expression analysis indicated that the pattern of expression change of OsGRF10 was almost identical to that of the cell division marker, OsCDKB2 (Figure 6(E) and Figure 6(G)).

It has been reported that miR396 regulates the expression of their target genes, GRFs, in both Arabidopsis and rice [37] [38]. OsmiR396c is one of multiple OsmiR396 loci in rice, and 11 of the 12 OsGRFs in the rice genome have a miR396 target site [24]. It has been shown that overexpression of OsmiR396d caused a similar effect to the knockdown of OsGRF6 and OsGRF10, and downregulation of the expression of most GRFs [36]. Thus, it is likely that miR396 negatively regulates GRF expression during leaf development. The expression level of OsmiR396c was highest in P4-7, not in the basalmost part of the $\mathrm{P} 4$ (P4-7), in the early and middle stages in wild-type controls (Figure 6(I)). Based on the OsCDKB2 expression pattern, P4-7 was predicted to be a transition region where active cell division is inactive. Thus, the expression pattern of OsmiR396c suggested that OsmiR396 acts to maintain the transition region by suppressing OsGRFs, although the accumulation pattern of mature miR396 along the P4 leaf axis should be determined in future studies.

\subsection{Changes in Expression of Marker Genes in Various Morphogenetic Mutants}

We performed expression analysis using marker genes to examine leaf development of several known mutants. 
Our results showed that expression of at least one of these marker genes was affected in most of the mutants, indicating that the set of marker genes used in this study can detect genetic and developmental alterations in most of the mutants. Only the $l g$ mutant did not show any changes in gene expression pattern. To our knowledge, $l g$ shows no abnormalities other than in ligule, auricle, and lamina joint formation during leaf development, although LG1 expression in the leaf sheath was reported [25]. Therefore, our results were consistent with previous knowledge about $l g$ and suggested that $L G$ does not affect leaf growth pattern during development.

The expression peaks of all marker genes examined were unaffected in the $d l$ mutant (Figure 7(Q)). This suggests that $d l$ mutation does not influence leaf development along the apical-basal axis. However, the expression level of OsTCP12 was elevated at the middle part of P4. The expression of DL in the P4 leaf were specifically detected in the central region abaxial to the central vascular bundle, and $D L$ is known to be responsible for thickening of the tissue by promoting cell proliferation during leaf development [26] [27]. This suggests that the elevated OsTCP12 expression in $d l$ is related to the altered cell proliferation pattern in the leaf primordia that was not represented by OsCDKB2 expression. Thus, it is possible that OsTCP12 modulates leaf shape by repressing cell proliferation in the middle part of $\mathrm{P} 4$ independent of the major cell proliferation process in the basalmost part of $\mathrm{P} 4$.

In the case of $d 61$, the expression patterns of all marker genes were also similar to those in the wild-type, but expression levels were increased in the apical and middle parts of P4 (Figure 7(R)). As $d 61$ is a loss-of-function mutant of the brassinosteroid receptor OsBRI1 [28], our results suggest that impaired brassinosteroid signaling does not disturb leaf development along the apical-basal axis. However, OsTCP12 expression was elevated in the middle part of P4. Although BR is known to regulate mainly cell elongation rather than cell proliferation in rice leaves, some reports suggested that BR also regulates cell proliferation in Arabidopsis [39]. In addition, BR-deficient mutants showed a strong phenotype with severely malformed leaf blades. Thus, elevated OsTCP12 expression could be related to changes in cell proliferation pattern in the $d 61$ leaf blade, although the degree of morphological alteration would be subtle in the $d 61$ allele used in this study.

In contrast to $d 61$, the expression patterns of marker genes in $d 1$ were very different from those in the wildtype controls (Figure 7(S)). The expression patterns of OsCDKB2 and OsGRF10 in $d 1$ were similar to those in the middle stage of wild-type (Figure 7(N)), and that of OsmiR396c in $d 1$ was similar to the pattern seen in the late stage in wild-type controls (Figure 7(O)). In addition, the second expression peak of OsTCP12 was seen in P4-4 in the $d 1$ mutant, but in the early stage in wild-type controls (Figure $7(\mathbf{M})$ ). This suggests that the relative positions of expression peaks among the marker genes were shifted in $d 1$ leaf primordia. Although it is difficult to predict the types of changes occurring in the $d 1$ leaf primordia, our expression analysis indicated that the coordinated cell proliferation pattern would be impaired. In fact, $D 1$ was shown to regulate cell proliferation by affecting multiple signaling pathways, such as GA and BR [29] [40]. Thus, the alteration of expression pattern observed in $d 1$ would be a result of integrated defects in multiple pathways.

Although the resolution of expression change along the proximal-basal axis was low, the expression patterns of marker genes in $d 18$ were considered to be similar to those in the wild-type (Figure 7(T)). The $d 18 h$ mutant used in this study has a null allele of the GA biosynthetic gene, OsGA3ox2, and is predicted to contain a reduced level of bioactive GA [30]. As GA promotes cell elongation and cell proliferation, the similar expression profile may contradict the effect of GA on leaf development. However, P4 in $d 18$ was about five- to six-fold shorter than that in wild-type controls. Considering the change in $d 18$ expression according to the absolute scale of leaf length, the region in which active cell division occurs is more restricted in the basal region compared to the wild-type P4. Accordingly, GA may regulate the range of the region of cell proliferation in the developing leaf.

The expression patterns of marker genes in the pla1 P4 leaf at the middle stage were similar to those in wild-type controls at the late stage (Figure $7(\mathrm{U})$ and Figure $7(0)$, respectively). This indicated that the leaf stage based on the expression profile of marker genes was advanced compared to the actual developmental stage in pla1. This result was consistent with previous reports that pla1 showed precocious leaf maturation. However, the expression peak of OsTCP12 in pla1 was still similar to that in the middle stage of wild-type controls (Figure 7(U) and Figure 7(N), respectively). Accordingly, pla1 mutation affected the relative timing of expression peaks of some genes rather than affecting the entire process of leaf maturation.

\section{Conclusion}

We characterized the developmental progression of wild-type leaves. Our results revealed the dynamic transition 
of developmental events, in particular, from cell proliferation to cell differentiation in the P4 leaf primordium. We developed several molecular markers showing dynamic expression from tip to base of P4, and applied them to various morphogenetic mutants. The changes in expression patterns of marker genes varied among the mutants, indicating that our marker genes are useful for detecting genetic effects on the transition process from cell proliferation to cell differentiation during leaf development. Our strategy would also be useful for characterizing leaf development of other mutants by comparison with wild-type controls and related mutants as references.

\section{References}

[1] Endo, M., Nakayama, S., Umeda-Hara, C., Ohtsuki, N., Saika, H., Umeda, M. and Toki, S. (2012) CDKB2 Is Involved in Mitosis and DNA Damage Response in Rice. Plant Journal, 69, 967-977. http://dx.doi.org/10.1111/j.1365-313X.2011.04847.x

[2] Lee, J., Das, A., Yamaguchi, M., Hashimoto, J., Tsutsumi, N., Uchimiya, H. and Umeda, M. (2003) Cell Cycle Function of a Rice B2-Type Cyclin Interacting with a B-Type Cyclin-Dependent Kinase. Plant Journal, 34, 417-425. http://dx.doi.org/10.1046/j.1365-313X.2003.01736.x

[3] Gonzalez, N., Vanhaeren, H. and Inzé, D. (2012) Leaf Size Control: Complex Coordination of Cell Division and Expansion. Trends in Plant Science, 17, 332-340. http://dx.doi.org/10.1016/j.tplants.2012.02.003

[4] Verkest, A., Manes, C.L., Vercruysse, S., Maes, S., Schueren, E.V.D., Beeckman, T., Genschik, P., Kuiper, M, Inzé, D. and Veyldera, L.D. (2005) The Cyclin-Dependent Kinase Inhibitor KRP2 Controls the Onset of the Endoreduplication Cycle during Arabidopsis Leaf Development through Inhibition of Mitotic CDKA;1 Kinase Complexes. Plant Cell, 17, 1723-1736. http://dx.doi.org/10.1105/tpc.105.032383

[5] Li, C., Potuschak, T., Colón-Carmona, A., Gutiérrez, R.A. and Doerner, P. (2005) Arabidopsis TCP20 Links Regulation of Growth and Cell Division Control Pathways. Proceedings of the National Academy of Sciences of the United States of America, 102, 12978-12983. http://dx.doi.org/10.1073/pnas.0504039102

[6] Kim, J.H., Choi, D. and Kende, H. (2003) The AtGRF Family of Putative Transcription Factors Is Involved in Leaf and Cotyledon Growth in Arabidopsis. Plant Journal, 36, 94-104. http://dx.doi.org/10.1046/j.1365-313X.2003.01862.x

[7] Liu, D., Song, Y., Chen, Z., and Yua, D. (2009). Ectopic Expression of miR396 Suppresses GRF Target Gene Expression and Alters Leaf Growth in Arabidopsis. Physiologia Plantarum, 136, 223-236. http://dx.doi.org/10.1111/j.1399-3054.2009.01229.x

[8] Mecchia, M.A., Debernardi, J.M., Rodriguez, R.E., Schommer, C. and Palatnik, J.F. (2013) MicroRNA miR396 and RDR6 Synergistically Regulate Leaf Development. Mechanisms of Development, 130, 2-13. http://dx.doi.org/10.1016/j.mod.2012.07.005

[9] Rodriguez, R.E., Mecchia, M.A., Debernardi, J.M., Schommer, C., Weigel, D. and Palatnik, J.F. (2010) Control of Cell Proliferation in Arabidopsis thaliana by microRNA miR396. Development, 137, 103-112. http://dx.doi.org/10.1242/dev.043067

[10] Ichihashi, Y., Kawade, K., Usami, T., Horiguchi, G., Takahashi, T. and Tsukaya, H. (2011) Key Proliferative Activity in the Junction between the Leaf Blade and Leaf Petiole of Arabidopsis. Plant Physiology, 157, 1151-1162. http://dx.doi.org/10.1104/pp.111.185066

[11] Li, P., Ponnala, L., Gandotra, N., Wang, L., Si, Y., Tausta, S.L., Kebrom, T.H., Provart, N., Patel, R., Myers, C.R., Reidel, E.J., Turgeon, R., Liu, P., Sun, Q., Nelson, T. and Brutnell, T.P. (2010) The Developmental Dynamics of the Maize Leaf Transcriptome. Nature Genetics, 42, 1060-1067. http://dx.doi.org/10.1038/ng.703

[12] Nelson, T. (2011) The Grass Leaf Developmental Gradient as a Platform for a Systems Understanding of the Anatomical Specialization of $\mathrm{C}_{4}$ Leaves. Journal of Experimental Botany, 62, 3039-3048. http://dx.doi.org/10.1093/jxb/err072

[13] Wang, L., Czedik-Eysenberg, A., Mertz, R.A., Si, Y., Tohge, T., Nunes-Nesi, A., Arrivault, S., Dedow, L.K., Bryant, D.W., Zhou, W., Xu, J., Weissmann, S., Studer, A., Li, P., Zhang, C., LaRue, T., Shao, Y., Ding, Z., Sun, Q., Patel, R.V., Turgeon, R., Zhu, X., Provart, N.J., Mockler, T.C., Fernie, A.R., Stitt, M., Liu, P. and Brutnell, T.P. (2014) Comparative Analyses of $\mathrm{C}_{4}$ and $\mathrm{C}_{3}$ Photosynthesis in Developing Leaves of Maize and Rice. Nature Biotechnology, 32, 1158-1165. http://dx.doi.org/10.1038/nbt.3019

[14] Itoh, J.I., Nonomura, K.-I., Ikeda, K., Yamaki, S., Inukai, Y., Yamagishi, H., Kitano, H. and Nagato, Y. (2005) Rice Plant Development: From Zygote to Spikelet. Plant and Cell Physiology, 46, 23-47. http://dx.doi.org/10.1093/pcp/pci501

[15] Lea, P.J. and Leegood II, R.C. (1999) Plant Biochemistry and Molecular Biology. John Wiley\& Sons, Inc., New York, $364 \mathrm{p}$.

[16] Boudet, A.M. (2000) Lignins and Lignification: Selected Issues. Plant Physiology and Biochemistry, 38, 81-96. 
http://dx.doi.org/10.1016/S0981-9428(00)00166-2

[17] Evert III, R.F. (2006) Esau's Plant Anatomy: Meristems, Cells, and Tissues of the Plant Body: Their Structure, Function, and Development. John Wiley\&Sons, Inc., Hoboken, 601 p. http://dx.doi.org/10.1002/0470047380

[18] Smith, R.A., Schuetz, M., Roach, M., Mansfield, S.D., Ellis, B. and Samuels, L. (2013) Neighboring Parenchyma Cells Contribute to Arabidopsis Xylem Lignification, While Lignification of Interfascicular Fibers Is Cell Autonomous. Plant Cell, 25, 3988-3999. http://dx.doi.org/10.1105/tpc.113.117176

[19] Wang, Y., Chantreau, M., Sibout, R. and Hawkins, S. (2013) Plant Cell Wall Lignification and Monolignol Metabolism. Frontiers in Plant Science, 4, 1-14.

[20] Morita, K., Hatanaka, T., Misoo, S. and Fukayama, H. (2014) Unusual Small Subunit That Is Not Expressed in Photosynthetic Cells Alters the Catalytic Properties of Rubisco in Rice. Plant Physiology, 164, 69-79. http://dx.doi.org/10.1104/pp.113.228015

[21] Ogawa, S., Suzuki, Y., Yoshizawa, R., Kanno, K. and Makino, A. (2012) Effect of Individual Suppression of RBCS Multigene Family on Rubisco Contents in Rice Leaves. Plant, Cell \& Environment, 35, 546-553. http://dx.doi.org/10.1111/j.1365-3040.2011.02434.x

[22] Suzuki, Y., Ohkubo, M., Hatakeyama, H., Ohashi, K., Yoshizawa, R., Kojima, S., Hayakawa, T., Yamaya, T., Mae, T. and Makino, A. (2007) Increased Rubisco Content in Transgenic Rice Transformed with the "Sense" rbcS Gene. Plant and Cell Physiology, 48, 626-637. http://dx.doi.org/10.1093/pcp/pcm035

[23] Sharma, R., Kapoor, M., Tyagi, A.K. and Kapoor, S. (2010) Comparative Transcript Profiling of TCP Family Genes Provide Insight into Gene Functions and Diversification in Rice and Arabidopsis. Journal of Plant Molecular Biology and Biotechnology, 1, 24-38.

[24] Choi, D., Kim, J.H. and Kende, H. (2004) Whole Genome Analysis of the OsGRF Gene Family Encoding Plant-Specific Putative Transcription Activators in Rice (Oryza sativa L.). Plant and Cell Physiology, 45, 897-904. http://dx.doi.org/10.1093/pcp/pch098

[25] Lee, J., Park, J.-J., Kim, S.L., Yim, J. and An, G. (2007) Mutations in the Rice Liguleless Gene Result in a Complete Loss of the Auricle, Ligule, and Laminar Joint. Plant Molecular Biology, 65, 487-499. http://dx.doi.org/10.1007/s11103-007-9196-1

[26] Yamaguchi, T., Nagasawa, N., Kawasaki, S., Matsuoka, M., Nagato, Y. and Hirano, H.-Y. (2004) The YABBY Gene DROOPING LEAF Regulates Carpel Specification and Midrib Development in Oryza sativa. Plant Cell, 16, 500-509. http://dx.doi.org/10.1105/tpc.018044

[27] Ohmori, Y., Toriba, T., Nakamura, H., Ichikawa, H. and Hirano, H.Y. (2011). Temporal and Spatial Regulation of DROOPING LEAF Gene Expression That Promotes Midrib Formation in Rice. Plant Journal, 65, 77-86. http://dx.doi.org/10.1111/j.1365-313X.2010.04404.x

[28] Sakamoto, T., Kitano, H. and Fujioka, S. (2013) Genetic Background Influences Brassinosteroid-Related Mutant Phenotypes in Rice. American Journal of Plant Sciences, 4, 212-221. http://dx.doi.org/10.4236/ajps.2013.42028

[29] Ueguchi-Tanaka, M., Fujisawa, Y., Kobayashi, M., Ashikari, M., Iwasaki, Y., Kitano, H. and Matsuoka, M. (2000) Rice Dwarf Mutant d1, Which Is Defective in the $\alpha$ Subunit of the Heterotrimeric G Protein, Affects Gibberellin Signal Transduction. Proceedings of the National Academy of Sciences of the United States of America, 97, 11638-11643.

[30] Sakamoto, T., Miura, K., Itoh, H., Tatsumi, T., Ueguchi-Tanaka, M., Ishiyama, K., Kobayashi, M., Agrawal, G.K., Takeda, S., Abe, K., Miyao, A., Hirochika, H., Kitano, H., Ashikari, M. and Matsuoka, M. (2004) An Overview of Gibberellin Metabolism Enzyme Genes and Their Related Mutants in Rice. Plant Physiology, 134, 1642-1653. http://dx.doi.org/10.1104/pp.103.033696

[31] Miyoshi, K., Ahn, B.O., Kawakatsu, T., Ito, Y., Itoh, J.I., Nagato, Y. and Kurata, N. (2004) PLASTOCHRON1, a Timekeeper of Leaf Initiation in Rice, Encodes Cytochrome P450. Proceedings of the National Academy of Sciences of the United States of America, 101, 875-880. http://dx.doi.org/10.1073/pnas.2636936100

[32] Kawakatsu, T., Itoh, J., Miyoshi, K., Kurata, N., Alvarez, N., Veit, B. and Nagato, Y. (2006) PLASTOCHRON2 Regulates Leaf Initiation and Maturation in Rice. Plant Cell, 18, 612-625. http://dx.doi.org/10.1105/tpc.105.037622

[33] Martín-Trillo, M. and Cubas, P. (2010) TCP Genes: A Family Snapshot Ten Years Later. Trends in Plant Science, 15, 31-39. http://dx.doi.org/10.1016/j.tplants.2009.11.003

[34] Yao, X., Ma, H., Wang, J. and Zhang, D. (2007) Genome-Wide Comparative Analysis and Expression Pattern of TCP Gene Families in Arabidopsis thaliana and Oryza sativa. Journal of Integrative Plant Biology, 49, 885-897. http://dx.doi.org/10.1111/j.1744-7909.2007.00509.x

[35] Kieffer, M., Master, V., Waites, R. and Davies, B. (2011) TCP14 and TCP15 Affect Internode Length and Leaf Shape in Arabidopsis. Plant Journal, 68, 147-158. http://dx.doi.org/10.1111/j.1365-313X.2011.04674.X

[36] Liu, H., Guo, S., Xu, Y., Li, C., Zhang, Z., Zhang, D., Xu, S., Zhang, C. and Chong, K. (2014) OsmiR396d-Regulated 
OsGRFs Function in Floral Organogenesis in Rice through Binding to Their Targets OsJMJ706 and OsCR4. Plant Physiology, 165, 160-174. http://dx.doi.org/10.1104/pp.114.235564

[37] Debernardi, J.M., Rodriguez, R.E., Mecchia, M.A. and Palatnik, J.F. (2012) Functional Specialization of the Plant miR396 Regulatory Network through Distinct microRNA-Target Interactions. PLoS Genetics, 8, e1002419. http://dx.doi.org/10.1371/journal.pgen.1002419

[38] Sunkar, R., Girke, T., Jain, P.K. and Zhu, J.K. (2005) Cloning and Characterization of microRNAs from Rice. Plant Cell, 17, 1397-1411. http://dx.doi.org/10.1105/tpc.105.031682

[39] Nakaya, M., Tsukaya, H., Murakami, N. and Kato, M. (2002) Brassinosteroids Control the Proliferation of Leaf Cells of Arabidopsis thaliana. Plant and Cell Physiology, 43, 239-244. http://dx.doi.org/10.1093/pcp/pcf024

[40] Oki, K., Inaba, N., Kitagawa, K., Fujioka, S., Kitano, H., Fujisawa, Y., Kato, H. and Iwasaki, Y. (2009) Function of the $\alpha$ Subunit of Rice Heterotrimeric G Protein in Brassinosteroid Signaling. Plant and Cell Physiology, 50, 161-172. http://dx.doi.org/10.1093/pcp/pcn182 